\title{
A Study of Email and SMS use in Rural Indonesia
}

\author{
Dean M.G. Hargreaves \\ University of Technology, Sydney \\ Broadway, Ultimo, Sydney, NSW 2007 \\ dean@it.uts.edu.au
}

\author{
Toni Robertson \\ University of Technology, Sydney \\ Broadway, Ultimo, Sydney, NSW 2007 \\ toni@it.uts.edu.au
}

\begin{abstract}
This paper describes a two-year research study that piloted and evaluated the use of low-cost, low-bandwidth Information and Communications Technology (ICT) to support meetings between agricultural researchers and farmers in rural Indonesia and researchers in Australia. We found that the primary constraints to ICT use in rural Indonesia are rarely technical, but rather relate to the knowledge, social and economic systems within which they are used. This study revealed how different local appropriations of email and mobile phone SMS clash, which often resulted in misunderstanding, frustration and reduced team cohesion and performance. This research contributes to understanding the role of ICT to enhance social inclusion of those in remote parts of developing countries.
\end{abstract}

\section{Author Keywords}

Low-cost, low-bandwidth, ICT4D, developing countries, action research, systems thinking and practice. Indonesia

\section{ACM Classification Keywords}

H5.m. Information interfaces and presentation (e.g., $\mathrm{HCI})$ : Miscellaneous.

\section{INTRODUCTION}

This study was stimulated by a desire to better understand the gap between the significant expectations for ICTs to enhance the social and economic well-being of those in developing countries and their actual use, value and impact. The history of ICT based interventions in developing countries has been a problematic one, and is typified by significant investments in hardware and software with little attention given to the social, human and cultural contexts of use (Warschauer 2004).

This research attempts to extend the findings of previous research that was conducted in rural Australia that demonstrated that low-cost, low-bandwidth ICTs can in fact be valued and used for meetings between scientists, farmers and their advisers if certain social and knowledge constraints were relieved (Hargreaves and McCown 2008). Could the findings from research in the use of ICTs in rural Australia be applied to a developing country context given the additional complexity imposed by distance, culture and language? Encouraged by experience in Australia, the researchers set out to learn if and under what circumstances ICTs could be used to conduct regular project meetings between Australian and

OZCHI 2009, November 23-27, 2009, Melbourne, Australia. Copyright the author(s) and CHISIG

Additional copies are available at the ACM Digital Library (http://portal.acm.org/dl.cfm) or ordered from the CHISIG secretary (secretary@chisig.org)

OZCHI 2009 Proceedings ISBN: 978-1-60558-854-4
Indonesian research teams, and create opportunities for Indonesian researchers, extension staff and farmers to discuss research results and extension information with their Australian colleagues.

Three existing joint projects between the Australian Centre for International Agricultural Research (ACIAR) and the Commonwealth Scientific and Industrial Research Organisation (CSIRO) were selected as case studies to pilot and evaluate a number of low-cost, lowbandwidth ICTs. These projects were between Australia and Indonesia, South Africa and Bangladesh respectively.

This paper reports on findings from a study of SMS and email use among agricultural researchers in Indonesia and Australia. The findings identified two different local appropriations of ICT that while highly effective within each group, and which often led to frustration and reduced communication efficacy when used between groups.

This paper is structured to first provide context and background to the research and is followed by a description of the research study which leads to results and discussion then conclusions.

\section{BACKGROUND}

This project was initiated by CSIRO, funded by ACIAR and was conducted over two years between 2005 and 2007. ACIAR is an Australian Government statutory authority that funds and commissions agricultural research for the benefit of developing countries, primarily in the Asia-Pacific and Southern Africa.

Travel to partner countries is an essential activity for ACIAR programme managers and for CSIRO researchers in undertaking development and research projects. However, travel incurs substantial costs and carries with it risks associated with security and personal health and safety. ACIAR and CSIRO commissioned this research to better understand the potential for ICT to reduce international travel, and its associated costs and risks, and to evaluate the role of ICT to improve project efficiency and efficacy through improved team-work and communication and .

There are 81 million mobile phones in use in Indonesia, and with a population of 232 million people, slightly more than 1 in 3 people have a mobile phone. The leading mobile network provider is Telkomsel who claim to cover $95 \%$ of the population. A description of the research study is presented in the next section.

\section{RESEARCH STUDY}

A group of CSIRO Agricultural researchers was assigned to work with farmers in Sulawesi, Indonesia to develop ways to grow higher-quality forages - a type of plant used 
to feed cattle. This group included an economist, an agricultural researcher with expertise in the computer based simulation of farming systems, a field technician with experience in forages and two additional researchers from the University of Queensland with specialisation in social science. This team travelled to Makassar, on the Island of Sulawesi in May 2004, and then to Mataram in Lombok in late-March 2005. Each trip consisted of a stay of approximately 10 days.

This team worked with researchers from Hasanuddin University and the local agricultural extension service BPTP in Makassar and agricultural extension staff from the University of Mataram and BPTP staff in Mataram. The relationship between research and extension activity is much the same in Indonesia as it is in Australia. In a traditional sense the expected role of researchers is to generate new knowledge, with the extension officers then expected to disseminate the results to farmers by direct interaction, presentations to farmer groups and through publishing booklets and handouts. The author accompanied the agricultural research teams on both occasions and undertook two programmes of integrated field-work: a technical programme that set-up, tested and supported deployment of appropriate ICTs and a second ethnographic study.

This research draws on the theory of action research to help structure the technical and field-work activities together. This included: 1. identifying and negotiating working arrangements with collaborating ACIAR research projects; 2. conducting joint analysis with researchers in these projects about the potential for ICT to enhance aspects of project operations; 3 . developing joint research plans with collaborating projects; 4 . identifying stakeholders and conducting baseline interviews; 5 . conducting local site ICT surveys; 6. undertaking a survey of currently available and potentially suitable ICT; 7. deploying technology and providing necessary training; and, 8. conducting a series of interviews evaluating the experience of using the various ICTs.

\section{Ethnographic field-work}

The lead researcher undertook 16 semi-structured interviews with Indonesian agricultural researchers, managers, technical field staff, IT support staff and extension staff, as well as the vice-chancellor of an Indonesian university. Interviews were conducted with Australian agricultural researchers, technical staff and managers that had travelled to Indonesia as part of the research. Further interviews were undertaken with research managers at ACIAR. Visits were made to each site that included observations on the availability and condition local ICT systems. The results of the fieldwork are presented in the next section. These interviews and observations contributed significantly to guiding choices for which ICT's to introduce.

\section{Technical field-work}

Four site surveys were conducted, one each at Hasanuddin University and BPTP in Makassar and the University of Mataram and BPTP in Mataram. These involved documenting ICT capacity at each site and jointly evaluating with local staff what ICT would be desirable to introduce.

We conducted 17 online meetings that piloted a variety of software and hardware tools. The software we piloted included: Microsoft NetMeeting, Windows Messenger, Skype, and eConf. Hardware we piloted included: Polycom VSX 7000 and VS100 room based VC units, Polycom multipoint conference units (MCU); INMARSAT based portable data terminals, and; Optus VSAT (Very Small Aperture Terminals) data terminals, which in effect are small satellite dishes.

Additionally, we piloted mobile phone based Short Message Service (SMS) together with a plug-in that allows users to send and receive SMS messages directly from Microsoft Outlook or from Skype- which is the focus of this paper. The next section presents results and discussion.

\section{RESULTS AND DISCUSSION}

A central theme that emerged was the way Australian researchers and Indonesian researchers appropriated technology in different ways, which in turn resulted in different patterns of use. This often caused frustration and misunderstanding between team members which at times resulted in project delays or misunderstandings. Other significant themes that emerged include: institutional and cultural influences on the way technology was used; the effects of social and organisational networks on technology use and issues concerning researchers modalities of work and technology use.

\section{Modalities of work and technology use}

By far the most significant issue emerging from the research was the different ways Indonesian researchers and Australian researchers had each appropriated email and mobile phones and the impact of this on their modalities of work. A modality of work is commonly referred to as the methods and procedures of an individuals work practice. Modalities of work are often highly idiosyncratic and are influenced by factors such as position within an organisation, role, cognitive factors and institutional issues (Nardi and Whitaker 2002).

While Australian researchers cited email as their primary means of communication with colleagues, Indonesian researchers cited mobile phone based Short Message Service (SMS) as their most used communication tool. Australian researchers had previously known that SMS use was prevalent among Indonesian researchers; however, this research revealed it to be far more widespread and instutionalised than expected. In fact Indonesian researcher SMS use in many ways mirrored Australian researcher email use.

Indonesian researchers used SMS as their primary means of communication, with email then mobile phone voice second and third preferences. However, Australian researchers used email, landline phone then mobile phone in order of both frequency of use and preference. While Indonesian researchers were proficient in all tools, the Australian researchers were only comfortable using email and voice calls on landline and mobiles for voice call, but were much less comfortable using SMS. Frequency of email use by Indonesian researchers was low due to the 
unreliable and often unworkably slow Internet connections at research offices; involvement in work that often required travel and, limited access to wired internet connections while out of the office. Mobile phone based SMS was almost always accessible due to near ubiquitous mobile phone coverage. The most common result of this asymmetry - in mobile phone and email use - was to slow project communications and progress; increase errors in joint activities and increased frustration among researchers.

The frustration related to a perceived lack of communication responsiveness from Indonesian researchers, and concurrent puzzlement by Indonesian researchers at the Australians persistence in using email which the Indonesians only used infrequently. This issue manifested itself in two ways: unacceptably long delays for email responses, often days or weeks, and unreturned phone calls to the Australians.

\section{Patterns of mobile phone use}

In general it was observed that Australian researchers were increasingly using work provided mobile phones for voice calls in preference to landlines. However they were also reluctant to use advanced features of their phones. One researcher who carried a sophisticated phone with large screen, video, photo capability and email remarked:

"I don't use many of these features, as I don't understand how to use them... my PA will ring me if there are any important emails or problems, and she can sort out the rest." (Australian Researcher)

All Indonesian researchers we interviewed travelled frequently as part of their work which often involved travel to remote locations where they could not access fixed-line telephone networks. Thus, Indonesian researchers preferred mobile phone voice calls to landline calls, as mobile phones better matched their modalities of work.

Mobile call rates are relatively cheap by Australian standards, as is the cost of sending an SMS message. All researchers used basic model phones, except those in senior positions who almost uniformly used mobiles with advanced features (eg cameras and large screens). In contrast to those Australian researchers with advanced mobile phones, the senior Indonesian researchers displayed good understanding of functionality and were observed to use these features as part of their normal work routine.

\section{Australian researchers use of SMS}

Australian researchers reported a low-level of SMS use. Out of seven Australian researchers interviewed, only two had reported having ever used SMS, and only one used it more than once a month. Their messages were shorter than their Indonesian colleagues and they tended to be used for a restricted set of activities. Australian researchers viewed SMS as relatively inconvenient compared to other forms of communications. One researcher described SMS as follows:

"I hardly used SMS text messaging at all... happy birthday and stuff like that, even though I had a mobile phone. This is my third one, I've had them for 8 years, never used the facility much.” (Australian researcher)

"Clunky, awkward. I've got big fingers." (Australian researcher)

The motivation for SMS use among Australian researchers was the additional contact it proved to family members in Australia while traveling in Indonesia, and due to the benefits of increased access it provided to members of the Indonesian team.

It is interesting to note that for one researcher seeing the value of SMS opened the door to the potential for other ICT's such as videoconferencing and web based collaborative tools. This experience led to the researchers increased use of SMS.

"I didn't know that until some time on my last trip, from that its made me think more about other communication options, what else would be effective, we look again at meetings, or we look again at video conferencing as opposed to sitting round the phone." (Australian Researcher)

Australian researchers did not replace their email communication with Indonesian researchers with SMS but rather adapted a hybrid approach, where they would use SMS as a way of alerting their Indonesian colleagues to an email that they had recently sent.

"... it is much more effective sending an SMS now than it is going through email. But if it is complex, SMS has a limit, if it is too long the message would be broken up into 2 or 3 parts if they are too long, its still more efficient if you have a fairly complex request to put in writing in an email in a very structured way" (Australian researcher)

\section{Indonesian researcher use of SMS}

Indonesia researchers patterns of SMS use differ markedly from their Australian colleagues. All 11 Indonesian researchers interviewed used SMS as their primary means of communication with their in-country colleagues, and Indonesian researchers reported frequent SMS use:

"I SMS very frequent, maybe 30 times a day. With colleagues, with friends with supervising staff. Maybe every 10 minutes in my office I get an SMS and I have to respond. It's very cheap. But I don't know how to send SMS to Australia?" (Indonesian researcher)

Whereas Australian researchers used SMS primarily for organising travel and alerting colleagues to check their email, Indonesian researchers used SMS for a wider set of tasks, including: checking on colleagues research progress, ordering seed, ordering library reprints and as part of supervising staff. They were also more likely to send longer SMS messages as part of more complicated requests than the Australians. They valued the immediacy of SMS and the access it provided while traveling, and it's relatively low cost. One Indonesian researcher described a pragmatic solution to the inability of most mobile phones to store more then a few messages. This researcher transcribed stored text messages into a notebook, which he then kept for later reference.

\section{Institutional and cultural aspects of tech. adoption} We found that the adoption of new technology and new practices was significantly influenced by institutional norms and culture. This research revealed a fascinating 
dichotomy between normative institutional aims declared by senior management with respect to the use of ICT, and the actions of those responsible for project implementation and management. Senior managers declared that international air travel should be reduced, due to occupational health and safety risks, security concerns and the expense. However, project managers those responsible for actually delivering the research were typically less enthusiastic, due in part to the perceived risk of using unfamiliar technology, the cost in time of learning how to use the new technology, and the additional effort required to modify well-tested and effective modalities of work.

Project managers often found international air travel a desirable aspect of their job - while this was not uniform there was a reluctance to declare this openly. One Australian researcher stated at the start of the project that:

\footnotetext{
"This technology looks great, and you've done some impressive things... but I'm personally not going to use it-it won't reduce my travel" (Australian funding agency manager)
}

At present there exist clear institutionally derived disincentives for project managers to adopt novel ICT and processes to support project operations. It was observed that travel is at times used by managers as a form of discretionary tacit reward for their staff. The situation could be improved by better aligning declared organisational priorities with tacit reward systems that encourage evaluation and adoption of novel technology. This could be further improved by implementing procesess that create better alignment between institutional aspirations to realise the substantial potential benefits of novel ICT and the practical matters facing project managers - including their personal motivations and individual modalities of work.

\section{Economic imperatives}

There were clear economic factors governing the use and adoption of technology and practices. Indonesian researchers looked constantly for cost savings in their operations. Indonesian institutions provided only very limited budgets for ICT which often meant, for instance, that researchers could not readily make international telephone calls. Researchers purchased their own mobile phones and used pre-paid credit to make calls and to send SMS messages. Often they were observed to 'run out of credit', and as a budgeting measure then tended to use SMS in preference to voice where possible- due to the significantly lower cost.

An interesting and counter-intuitive by-product of fewer resources was the innovation that this generated among research work practice and technology use. Indonesian researchers actively sought new technology that would improve convenience, the quality and frequency of communication with each other while reducing cost which drove them to adopt novel ICT's and practices. In contrast Australian researches were well funded with ample budgets for telecommunications. While on the surface this appears to be an advantage, an interesting and unintended consequence is to reduce motivation for innovative behaviour with respect to work practices and use of new technology.

\section{CONCLUSIONS}

This study discuses different local appropriations of email and SMS among Agricultural researchers working together on joint activities in Indonesia and Australia. Counter intuitively, the lack of resources which is often a feature of developing country research institutions appears to encourage innovative behaviour and adoption of new technology and work practices rather then act as a hindrance. The Indonesian researchers appreciated the increased access the technology provided to Australian researchers, while the Australian researchers valued the increased ability to more effectively manage projects remotely and to and monitor progress. Mobile phones and SMS increased the frequency and potential for add-hoc, serendipitous communications, once the Australian researchers had adapted their practice. We found that the different social and economic situations of Australian and Indonesian researchers resulted in different local appropriations of technology and this was found to cause conflict and was at times detrimental to the teams performance.

Drawing on the theory and practice of Action Research as a way to structure the research ensured that the researcher worked together with research subjects in identifying issues, and then co-designing solutions. While the outcomes of this approach were valued by participants as evidenced by the continued us of SMS and new work practices after the project finished - some participants expressed concern that the additional time and effort that an Action Research approach required. The increased opportunities that these technologies provide to connect people living and working in rural Indonesia with researchers in Australia has the effect of enhancing both social inclusion and opportunities for access to information and expertise. Using simple robust low-cost ICT as part of international R\&D projects in developing countries can encourage serendipitous and spontaneous communication and has the potential to improve team performance due to more timely communication.

Future directions of this research may include the application of the theory of social inclusion as a way to analyse the introduction of new technology into communities, and the ability of those people to engage in locally relevant and meaningful social practices.

\section{ACKNOWLEDGMENTS}

This research was conducted by the Commonwealth Scientific and Industrial Research Organisation (CSIRO) and generously supported by the Australian Centre for International Agricultural Research (ACIAR).

\section{REFERENCES}

Hargreaves, D. and B. McCown (2008). Low-cost, lowbandwidth online meetings between farmers and scientists, ACM New York, NY, USA.

Nardi, B. and S. Whitaker (2002). The Place of Face to Face Communication in Distributed Work Massachusetts, MIT Press.

Warschauer, M. (2004). Technology and social inclusion: Rethinking the digital divide, MIT Press. 


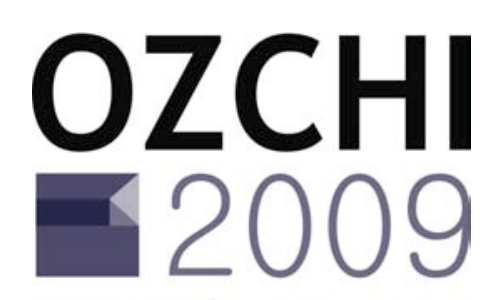

DESIGN | OPEN 24_7

OZCHI 2009, November 23-27, 2009, Melbourne, Australia.

Edited by Jesper Kjeldskov, Jeni Paay and Stephen Viller

Copyright the author(s) and CHISIG

Additional copies are available at the ACM Digital Library (http://portal.acm.org/dl.cfm)

or can be ordered from the CHISIG secretary (secretary@chisig.org)

ISBN: 978-1-60558-854-4 


\section{review process}

The OZCHI 2009 conference held in Melbourne, Australia 23-27 November 2009 received 60 long paper and 88 short paper submissions. From these submissions, 32 long and 42 short papers were selected to appear at the conference. All submitted long and short papers were subjected to double-blind peer review by an independent international reviewing committee of 131 people. Long and short papers were reviewed in their entirety by at least three peers. Industry case studies, panels, and workshop and tutorial proposals were reviewed by their respective co-chairs.

The OZCHI 2009 Proceedings is published by CHISIG and will be available from the ACM digital library shortly after the conference (http://portal.acm.org/dl.cfm). Additional copies can also be ordered from the CHISIG secretary (secretary@chisig.org)

\section{Conference and proceedings details}

The 21st Annual Conference of the Australian Computer-Human Interaction Special Interest Group, OZCHI 2009, 23-27 November 2009, Melbourne, Australia

Proceedings of OZCHI 2009 - Design: Open 24/7

Edited by Jesper Kjeldskov, Jeni Paay and Stephen Viller

Published by CHISIG, Melbourne, Australia (2009)

ISBN no 978-1-60558-854-4

\section{reviewers}

Alexander De Luca

Alexia Fry

Andreea Niculescu

Andrew Dekker

Andrew Vande Moere

Baki Kocaballi

Barney Dalgarno

Ben Kraal

Benjamin Close

Bernd Ploderer

Beryl Plimmer

Bharat Dave

Brendan Ryder

Bruce Thomas

Chao-Lung Lee

Christine Satchell

Christopher Lueg

Clint Heyer

Connor Graham

Daniel Salber

Danielle Wilde

Daryl Ku

David Ahlstrøm

David Jones

David Nichols

Dean Hargreaves

Dharani Perera-Schulz

Dimitrios Raptis

Duncan Stevenson

Elizabeth Kemp

Erik Champion

Flora Dilys Salim

Frank Maguire
Frank Vetere

Fraser Anderson

Gavin Sade

Gerry Gaffney

Gloria Gomez

Greg Wadley

Gregor McEwan

Guillaume Gibert

Hanif Baharin

Harald Holone

Hilal Al Maqbali

Hilary Davis

Holger Regenbrecht

Huanglingzi Liu

Hugh Macdonald

Hyewon Kim

Jan Seeburger

Jan Stage

Jane Li

Janne Jul Jensen

Jason Yang

Jeremy Yuille

Jeni Paay

Jesper Kjeldskov

Jo Vermeulen

John Grundy

John Murphy

Jolynna Sinanan

Jon Pearce

Jonas Fritsch

Julie Maitland

Kari-Jouko Räihä

Kasper Hornbæk
Kasper Løvborg Jensen

Keith Cheverst

Kenton O'Hara

Kim Halskov

Konstantinos Kazakos

Leila Alem

Lejla Vrazalic

Lian Loke

Linda Leung

Lorna Macdonald

Luc Julia

Marcus Foth

Margot Brereton

Maria Hakansson

Marianella Chamorro

Mark Billinghurst

Mark Gaved

Mark Rouncefield

Mark Toleman

Martin Brynskov

Martin Tomitsch

Masood Masoodian

Matthew Willis

Michael Pilling

Michelle Annett

Mikael B. Skov

Mike Broughton

Naisan Yazdani

Natalie Ebenreuter

Natasha Dwyer

Nick Taylor

Nilanthi Seneviratne

Nilma Perera
Pat Lehane

Patrick Watson

Penny Hagen

Peter Dalsgaard

Peter Jones

Ralf Muhlberger

Rene Hexel

Ricky Robinson

Rob Saunders

Ron van Schyndel

Saila Ovaska

Sandrine Balbo

Shawn Ashkanasy

Shiu Wen Wang

Silvia Fajardo-Flores

Sisira Adikari

Siu Man Carrie Lui

Sonja Pedell

Stefan Cronholm

Stefan Schutt

Steve Dillon

Supriya Singh

Susanne Tak

Syariffanor Hisham

Tek Yong Lim

Toni Robertson

Tuck Leong

Vesna Popovic

Victor Gonzalez

Vivienne Farrell

Wendy Hui

Yann Riche 